\section{Interleukin 6 Is Associated with Pulmonary Involvement in Primary Sjögren's Syndrome}

\section{To the Editor:}

Primary Sjögren's syndrome (pSS) is an autoimmune disease characterized by lymphocytic infiltration leading to destruction of acinar and ductal cells and loss of glandular parenchyma. Although sicca symptoms are pivotal manifestations of pSS, extraglandular involvement also occurs. Pulmonary involvement in pSS consists of interstitial lung disease, obstructive small airway disease, pulmonary arterial hypertension (PAH), bullous disease, and lymphoma ${ }^{1}$.

Recent evidence suggests that cytokine-mediated mechanisms are critical in pSS, but the precise cytokine pattern driving lung injury remains unclear $^{2-4}$. Because of current availability of therapies that modulate selected cytokines, in-depth knowledge of the cytokine profile associated to specific tissue damage is necessary.

We analyzed circulating concentrations of several prototypical $T_{H} 1$ [interferon- $\gamma\left(\right.$ IFN- $\gamma$ )], $\mathrm{T}_{\mathrm{H}} 2$ [interleukin 4 (IL-4), IL-6, IL-10], and $\mathrm{T}_{\mathrm{H}} 17$ (IL-17) cytokines in patients with pSS according to the presence or absence of pulmonary involvement.

From an outpatient cohort with pSS according to the preliminary classification criteria ${ }^{5}$ we selected patients who had pulmonary involvement demonstrated by high-resolution computed tomography scans of the lungs, and at least one of the following: pulmonary function test, spirometry, or lung biopsy. For comparisons, we selected age and gender-matched pSS patients without pulmonary manifestations and normal chest radiograph. We excluded patients receiving immunosuppressants within the last year, while prednisone $\leq 10 \mathrm{mg}$ /day and antimalarials were allowed. Sera were collected and stored $\left(-70^{\circ} \mathrm{C}\right)$ until use. Cytokines were measured by ELISA (R\&D Systems, Minneapolis, MN, USA).

Differences between groups were estimated by chi-square or MannWhitney tests as appropriate. Associations were calculated with the Spearman coefficient correlation. All analyses were 2-tailed with a $p<0.05$ significance. Data were processed with the GraphPad Prism 4.0 software (GraphPad Inc., San Diego, CA, USA). The study protocol was approved by the local ethics committee and informed consents were obtained from all patients.

Five female patients with pSS with pulmonary involvement (mean age $47.6 \pm 19$ yrs) were included. Four patients had interstitial lung disease, 2 of them also having PAH; the remaining patient had bullous disease and PAH. As controls, 15 pSS patients (mean age $53.6 \pm 13$ yrs) without pulmonary involvement were studied. Except for a higher frequency of rheumatoid factor/IgM (RF) in patients with pulmonary involvement $(100 \%$ vs $47 \%$, respectively; $\mathrm{p}=0.03)$, the 2 groups were similar (Table 1$)$. Median IL-6 concentration in patients with pulmonary involvement was $5.6 \mathrm{pg} / \mathrm{ml}$ (range 2.4-29.3), while it was only $0.8 \mathrm{pg} / \mathrm{ml}$ in controls (range $0-23.1 ; \mathrm{p}=0.01$ ). Serum levels of IL-10 (median 0 , range $0-121 \mathrm{pg} / \mathrm{ml} \mathrm{vs}$ median 0 , range $0-95.1 \mathrm{pg} / \mathrm{ml}$, respectively; $\mathrm{p}=$ nonsignificant) and IL-17 (median 0 , range $0-0.1 \mathrm{pg} / \mathrm{ml}$ vs median 0 , range $0-353 \mathrm{pg} / \mathrm{ml} ; \mathrm{p}=$ nonsignificant) were similar (Figure 1), while concentrations of both IL-4 and IFN- $\gamma$ were undetectable. There were no significant correlations between high-sensitivity C-reactive protein and IL-6 or other cytokines (data not shown).

Thus, we found higher concentrations of IL-6 and RF, but not other cytokines or antibodies, in pSS patients with pulmonary involvement compared to patients without this manifestation. While this is the first study specifically to investigate the cytokine profile in patients with pSS and pulmonary involvement, there are few reports supporting our results. Hulkkonen, et al found plasma levels of IL-6 to be higher in pSS patients than in blood donors, and those patients with celiac disease, pulmonary fibrosis, or peripheral nervous system symptoms had significantly higher IL-6 levels than patients without these manifestations ${ }^{4}$. Similarly, GarcíaCarrasco, et al found higher serum IL-6 levels in pSS patients than in healthy controls; however, elevated IL-6 levels were observed in patients
Table 1. Selected clinical characteristics of patients with pSS. Except for proportions, results are expressed as mean $\pm \mathrm{SD}$.

\begin{tabular}{lccc}
\hline & $\mathrm{pSS} /$ Lung Disease, & $\mathrm{pSS}$ & $\mathrm{p}$ \\
& $\mathrm{n}=5$ & $\mathrm{n}=15$ & \\
\hline Female, $\mathrm{n}(\%)$ & $5(100)$ & $15(100)$ & - \\
Age, yrs & $47.6 \pm 19$ & $53.6 \pm 13$ & - \\
Disease duration, yrs & $6.8 \pm 4$ & $4.6 \pm 2.6$ & - \\
Xerostomia, $\mathrm{n}(\%)$ & $5(100)$ & $15(100)$ & - \\
Keratoconjunctivitis, $\mathrm{n}(\%)$ & $4(80)$ & $15(100)$ & - \\
Salivary gland biopsy, $\mathrm{n}(\%)$ & $4 / 4(100)$ & $5 / 5(100)$ & - \\
Leukocytes, $10^{3} / \mu \mathrm{l}$ & $6.96 \pm 1.8$ & $6.5 \pm 1.9$ & - \\
Neutrophils, $10^{3} / \mu 1$ & $4.12 \pm 1.5$ & $4.06 \pm 1.4$ & - \\
Lymphocytes, $10^{3} / \mu \mathrm{l}$ & $1.97 \pm 0.4$ & $1.82 \pm 0.6$ & - \\
Monocytes, $10^{3} / \mu \mathrm{l}$ & $0.45 \pm 0.3$ & $0.5 \pm 0.1$ & - \\
Eosinophils, $10^{3} / \mu \mathrm{l}$ & $0.37 \pm 0.2$ & $0.29 \pm 0.2$ & - \\
Hemoglobin, $\mathrm{g} / \mathrm{dl}$ & $14.2 \pm 1.4$ & $14.1 \pm 0.9$ & - \\
Platelets, $10^{3} / \mu \mathrm{l}$ & $266 \pm 47$ & $226 \pm 56$ & - \\
ESR, mm/h & $16.2 \pm 7$ & $28.3 \pm 16$ & - \\
Rheumatoid factor,$+ \mathrm{n}(\%)$ & $5(100)$ & $7(47)$ & 0.03 \\
Antinuclear antibodies $+\mathrm{n}(\%)$ & $3(60)$ & $11(73)$ & - \\
Anti-Ro/SSA,$+ \mathrm{n}(\%)$ & $1(20)$ & $6(40)$ & - \\
Anti-La/SSB $+\mathrm{n}(\%)$ & $1(20)$ & $5(33)$ & - \\
Anti-CCP2 $+\mathrm{n}(\%)$ & $0(0)$ & $0(0)$ & - \\
C3 complement*, mg/dl & $135 \pm 25$ & $115 \pm 23$ & - \\
C4 complement*, mg/dl & $21 \pm 7$ & $22 \pm 6$ & - \\
Antimalarials, $\mathrm{n}(\%)$ & $4(80)$ & $14(93)$ & - \\
Prednisone, $\mathrm{n}(\%)$ & $2(40)$ & $2(13)$ & - \\
\hline
\end{tabular}

* Normal range for C3 complement, 79-152 mg/dl; C4 complement, 16-38 mg/dl. ESR: erythrocyte sedimentation rate; Anti-CCP2: 2nd generation anti-cyclic citrullinated peptide antibodies.

with liver involvement, while in those with pulmonary involvement only trends for association were found ${ }^{3}$.

Although little is known about the role of IL-6 in the development of pulmonary injury in pSS, it is possible that the underlying mechanisms resemble those responsible in idiopathic pulmonary fibrosis (IPF) or in other autoimmune diseases. Fibroblasts are essential in scar formation, but they need to be cleared from the wound site as part of the normal tissue repair process. Uncontrolled fibroblast activation and proliferation leading to excessive collagen deposition are hallmarks of fibrosis, and it is hypothesized that insufficient apoptosis of fibroblasts contributes to the development of IPF ${ }^{6}$. In this regard, while IL- 6 enhances the Fas-induced apoptosis in normal fibroblasts, in fibroblasts from patients with IPF it acts as a potent inhibitor of apoptosis, through increased expression of antiapoptotic proteins, mainly of the $\mathrm{Bcl}-2$ family ${ }^{7,8}$. Interestingly, these profibrotic mechanisms of IL-6 are not limited to IPF. Systemic sclerosis is a prototypical fibrosant disease in which increased production of IL- 6 has been demonstrated. Further, serum IL-6 levels are able to not only discriminate between diffuse and limited cutaneous involvement in systemic sclerosis, but also to correlate significantly with pulmonary fibrosis and with a decline in vital capacity 9,10 .

It must be emphasized that our patients had a longterm established disease, and they were analyzed in a cross-sectional study. It would be interesting to perform longitudinal studies to evaluate the cytokine profile in early stages and throughout the course of the disease. Of note, the fact that 2 patients without lung damage had very high levels of IL-6 precludes their use as a reliable predictive factor for pulmonary involvement.

Our results suggest a possible pathogenic association of IL-6 and pulmonary involvement in patients with pSS. This result could be relevant, particularly as an anti-IL-6 agent may soon be available. 

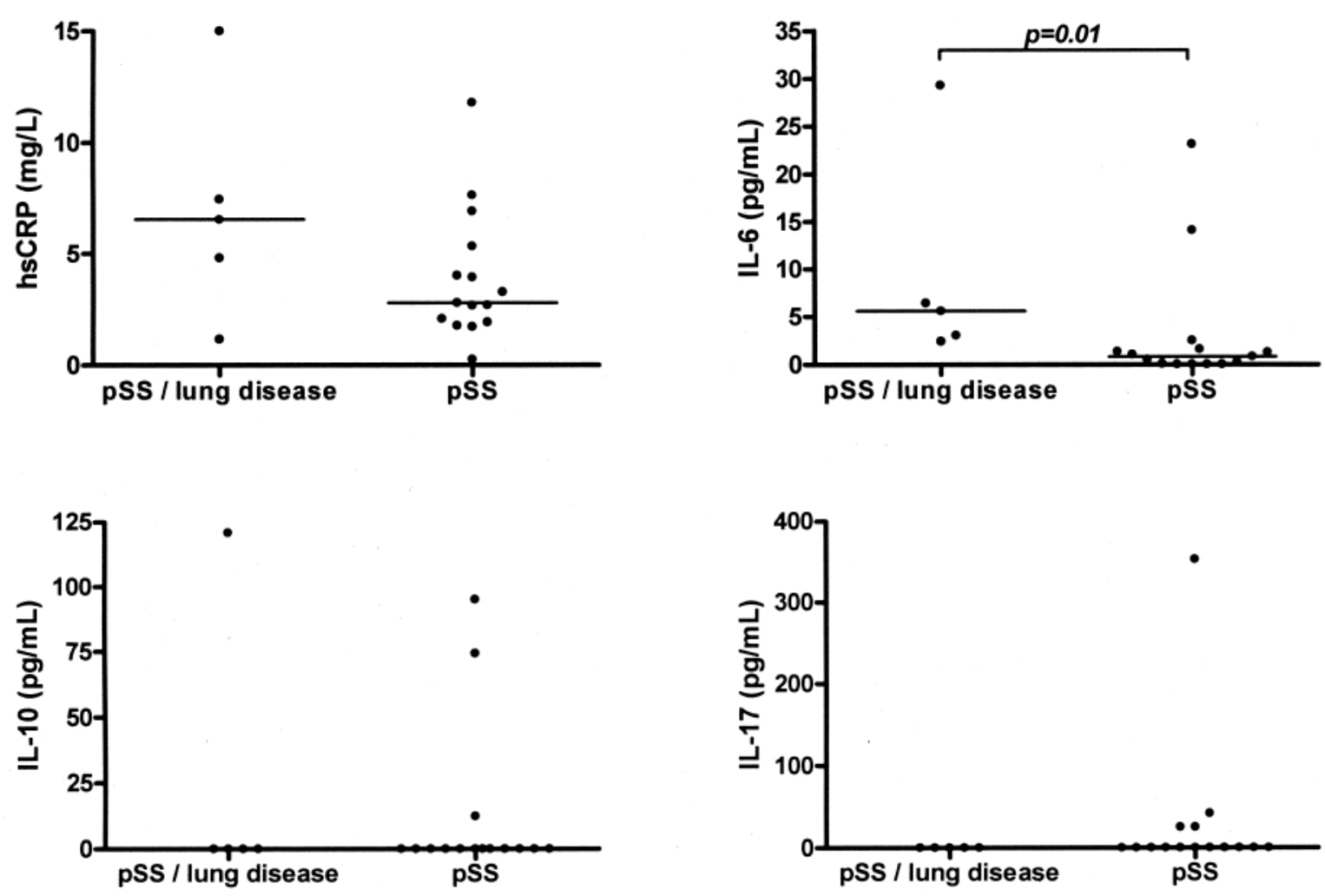

Figure 1. Serum concentrations of selected biomarkers. Levels of high-sensitivity C-reactive protein tended to be higher in patients with pulmonary involvement, although no significant difference was attained. The median IL-6 concentration in patients with pulmonary involvement was $5.6 \mathrm{pg} / \mathrm{ml}$ (range 2.4-29.3), while it was only $0.8 \mathrm{pg} / \mathrm{ml}$ in controls (range 0-23.1; $\mathrm{p}=0.01$ ). Serum levels of IL-10 (median 0 , range $0-121 \mathrm{pg} / \mathrm{ml}$ vs median 0 , range $0-95.1 \mathrm{pg} / \mathrm{ml} ; \mathrm{p}=\mathrm{NS}$ ) and $\mathrm{IL}-17$ (median 0 , range $0-0.1 \mathrm{pg} / \mathrm{ml}$ vs median 0 , range $0-353$ $\mathrm{pg} / \mathrm{ml} ; \mathrm{p}=\mathrm{NS}$ ) were similar in the 2 groups. Horizontal lines denote median values.

RICARDO MÁRQUEZ-VELASCO, BSc, Department of Immunology; PEDRO RODRÍGUEZ-HENRÍQUEZ, MD, Department of Rheumatology; RAFAEL BOJALIL, MD, PhD, Department of Immunology, Instituto Nacional de Cardiología Ignacio Chávez; LUIS M. AMEZCUA-GUERRA, MD, Department of Immunology, Instituto Nacional de Cardiología Ignacio Chávez, LaSalle University School of Medicine, Juan Badiano 1, Sección XVI, Tlalpan, 14080, Mexico City, Mexico. Address correspondence to Dr. L.M. Amezcua-Guerra;

E-mail: 1mamezcuag@gmail.com

Supported by the Instituto Nacional de Cardiología Ignacio Chávez.

\section{REFERENCES}

1. Inokuma S. Pulmonary involvement in Sjögren's syndrome. Intern Med 2002;41:73-4.

2. Szodoray P, Alex P, Brun JG, Centola M, Jonsson R. Circulating cytokines in primary Sjögren's syndrome determined by a multiplex cytokine array system. Scand J Immunol 2004;59:592-9.

3. García-Carrasco M, Font J, Filella X, Cervera R, Ramos-Casals M, Sisó A, et al. Circulating levels of Th1/Th2 cytokines in patients with primary Sjögren's syndrome: Correlation with clinical and immunological features. Clin Exp Rheumatol 2001;19:411-5.

4. Hulkkonen J, Pertovaara M, Antonen J, Pasternack A, Hurme M. Elevated interleukin- 6 plasma levels are regulated by the promoter region polymorphism of the IL6 gene in primary Sjögren's syndrome and correlate with the clinical manifestations of the disease. Rheumatology 2001;40:656-61.
5. Vitali C, Bombardieri S, Moutsopoulos HM, Balestrieri G, Bencivelli W, Bernstein RM, et al. Preliminary criteria for the classification of Sjögren's syndrome. Results of a prospective concerted action supported by the European Community. Arthritis Rheum 1993;36:340-7.

6. Gharaee-Kermani M, Phan SH. Molecular mechanisms of and possible treatment strategies for idiopathic pulmonary fibrosis. Curr Pharm Des 2005;11:3943-71.

7. Moodley YP, Misso NL, Scaffidi AK, Fogel-Petrovic M, McAnulty RJ, Laurent GJ, et al. Inverse effects of interleukin- 6 on apoptosis of fibroblasts from pulmonary fibrosis and normal lungs. Am J Respir Cell Mol Biol 2003;29:490-8.

8. Tanaka T, Yoshimi M, Maeyama T, Hagimoto N, Kuwano K, Hara N. Resistance to Fas-mediated apoptosis in human lung fibroblast. Eur Respir J 2002;20:359-68.

9. Hasegawa M, Sato S, Fujimoto M, Ihn H, Kikuchi K, Takehara K. Serum levels of interleukin 6 (IL-6), oncostatin M, soluble IL-6 receptor, and soluble gp130 in patients with systemic sclerosis. J Rheumatol 1998;25:308-13.

10. Scala E, Pallotta S, Frezzolini A, Abeni D, Barbieri C, Sampogna $\mathrm{F}$, et al. Cytokine and chemokine levels in systemic sclerosis: relationship with cutaneous and internal organ involvement. Clin Exp Immunol 2004;138:540-6.

J Rheumatol 2009;36:11; doi:10.3899/jrheum.090572 